\title{
Solar Induction Cooker
}

\author{
Dr. S. Karim,Ph.D.,PEng.,CEng.,MIET, MIEEE \\ Professor, Department of Electrical and computer Engineering, Ryerson University, 350 Victoria Street, Toronto, \\ Ontario L5L 4K1, Canada, Phone :416 979 5000X6111,email: skarim@ryerson.ca
}

\begin{abstract}
There is no available power grid in the rural areas in many countries in South America, Asia and Africa. st places, Fossil fuel or wood is used for cooking. Besides environmental issues, fossil fuel and wood from trees are being depleted at a fast rate. Solar power is available everywhere during day time in all countries. This solar induction cooker uses a solar panel, which gives a variable dc, to charge a battery. The dc from the battery is converted to a high frequency ac voltage by an inverter circuit. This inverter circuit supplies alternating current to a coil on a magnetic core where alternating flux is produced. This alternating flux produces in the magnetic core Eddy current and Hysteresis 'losses' inside the magnetic core. In this application, these losses will produce useful heat. A cooking pot placed on the magnetic core will be used for cooking.
\end{abstract}

Key words: solar charger, Inverter, induction cooker

\section{Introduction}

The induction cooker now available in the market produces the high frequency flux when connected the $110 \mathrm{~V}, 60 \mathrm{~Hz}$ domestic supply. The concept of solar cooker is very useful when local utility supply is not available.

The principle of induction cooker: The following diagrams explain the operating principles of the solar cooker.

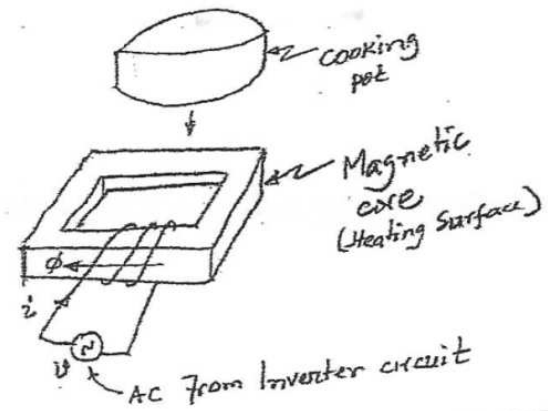

Figure-1: The Magnetic core and cooking pot to be placed on the core
The coil on the magnetic core is supplied by high frequency alternating current in the coil from an inverter, which converts DC from a battery to AC.

The heating in the magnetic is created by two phenomena; one is the Eddy current inside the magnetic core and the other is Hysteresis loop of the magnetic cycle. These two phenomena are briefly explained in the following diagrams.
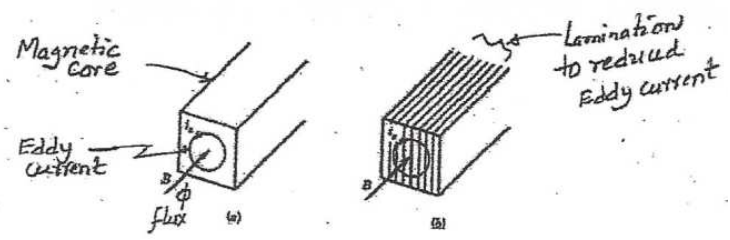

Figure-2: (a) Eddy current in un-laminated core,(b) Eddy current in Laminated core

The alternating flux due to alternating current in the coil will create Eddy current flow inside the core as shown. These eddy current will heat up the core. In normal cores in electric transformers and machines the magnetic cores are laminated to reduce the eddy current heating inside the transformer and electric machines. In the Induction cooker, the core is not laminated to have high value of eddy current losses.

$P_{e}=K_{e} f^{2} B_{\max }^{2}$

The equation- 1 shows the parameters which affects the eddy current power loss $\mathrm{P}_{\mathrm{e}} \cdot \mathrm{K}_{\mathrm{e}}$ depends on the type of core material used, $f$ is the frequency of the supply from the inverter, and $\mathrm{B}_{\max }$ is the maximum flux density $\left(\right.$ Tesla $=$ Weber $\left./ \mathrm{m}^{2}\right)$. For a particular core material, the Eddy current heat will increase with frequency and maximum flux density.

Another heating created inside the core is due to Hysteresis magnetic loop, which is shown in Figure-3. The ac current produces a flux loop as shown when the current is alternating. The flux in 
the core goes through loop. The area under the loop is a loss in the magnetic core. For a good magnetic core this area under the loop is narrow, but not so good magnetic material, this loop will be wider. For the induction cooker, the magnetic core need not be of high quality. A simple wrought iron will be good enough for this cooker.
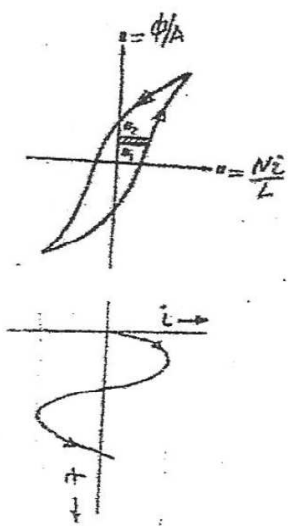

Figure-3: The Hysteresis loop created by the alternating current

$$
P_{h}=K_{h} . \text { Vol.f. } B_{\max }^{n}
$$

The Hysteresis loss $\mathrm{P}_{\mathrm{h}}$ depends on factor $\mathrm{K}_{\mathrm{h}}$, on the volume of the core, Vol, $\mathrm{f}$ is the frequency of the supply from the inverter and $B_{\max }$ is the maximum flux in the core, and $\mathrm{n}$ value ranges from 1.5 to 2.5 . $n$ may be taken as average $n=2$ for calculation.

The total heating in the core is the summation of $\mathrm{P}_{\mathrm{e}}+\mathrm{P}_{\mathrm{h}}$. However, most of the heating will be from $\mathrm{P}_{\mathrm{e}}$, Eddy current 'losses'.

\section{Functional Block diagram of the Solar Cooker}

The Figure- 4 below shows the functional Block diagrams of the total system.

\begin{tabular}{|c|c|c|c|c|c|c|c|}
\hline $\begin{array}{l}\text { Solar } \\
\text { Panel }\end{array}$ & $\begin{array}{l}\text { Char } \\
\text { Circ }\end{array}$ & \begin{tabular}{|c|}
$12 \mathrm{~V}$ \\
Battery
\end{tabular} & $=\begin{array}{r}\text { DC } \\
\text { Invert }\end{array}$ & & & & \\
\hline
\end{tabular}

Figure-4: Functional Block diagram of the Solar Induction Cooker

The Solar panel in Figure-4 gives variable DC voltage. This voltage depends day time sun shine. The DC from the Solar panel is used to charge a battery. In this case, a commonly available $12 \mathrm{~V}$ rechargeable battery is shown. The battery supplies power irrespective whether it is night or day.

\section{Battery Charging Circuit from Solar Panel}

All simulations were performed using MULTISIM of National Instruments

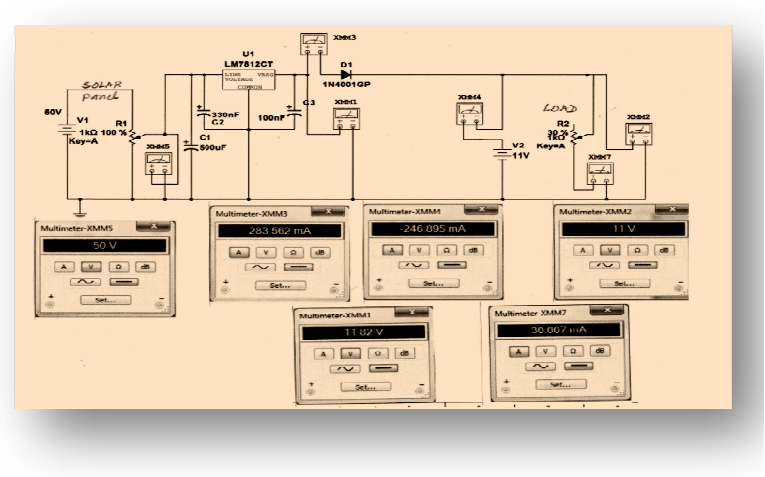

Figure 5: Charging circuit with meter readings when Solar panel gives $50 \mathrm{~V}$ and battery is $11 \mathrm{~V}$.

$\mathrm{U} 1$ is voltage regular chip LM7812CT. Diode D1 is used to block current flow from battery to solar panel if solar panel voltage drops below battery voltage (at night).

4. Inverter Circuit from $12 \mathrm{~V}$ battery to alternating current in magnetic coils

Figure-6 shows a MOSFET driven inverter circuit. The four MOSFETs Q1, Q2, Q3 and Q4 are turned $\mathrm{ON}$ by the positive signals in their respective gate terminals.

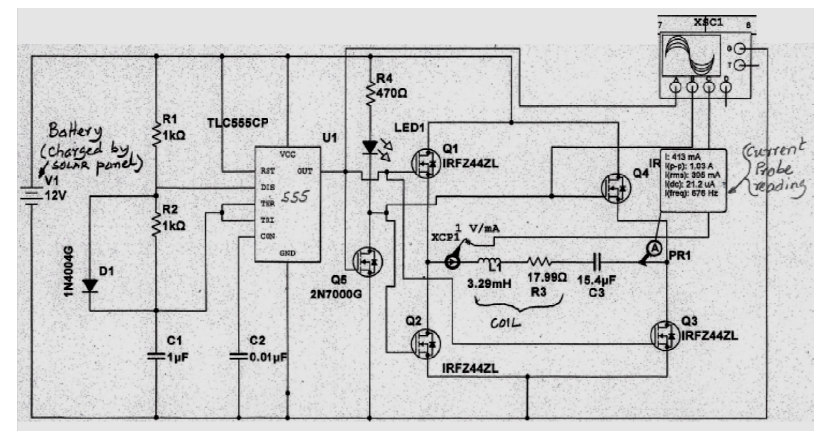

Figure-6: MOSFET driven Inverter circuit (to drive current through the coil)

Timer chip U1:TLC555CP produces the gate signals for the MOSFETS in the circuit. The voltage at the OUT terminal of 555 timer is a digital output, which is alternating between High and Low $(0 \mathrm{~V})$. These voltages are applied to the Gates of MOSFETS Q1 and Q3 to turn ON and OFF. To get a duty cycle of $50 \%$, diode D1 at the terminals of 555 is used.

The duration of $\mathrm{T}_{\mathrm{HIGH}}=0.7 \mathrm{R} 1 . \mathrm{C} 1$, and duration of $\mathrm{T}_{\text {LOW }}=0.7 \mathrm{R} 2 . \mathrm{C} 1$. For $50 \%$ duty cycle, $\mathrm{T}_{\text {High }}=\mathrm{T}_{\mathrm{LOW}}$ $=0.7 \mathrm{R} 1 . \mathrm{C} 1$ This makes the time period $\mathrm{T}=0.7(\mathrm{R} 1+\mathrm{R} 2) \cdot \mathrm{C} 1=0.7(2 \mathrm{R} 1) \mathrm{C} 1=1.4 \mathrm{R} 1 \mathrm{C} 1 . \quad$ For $\mathrm{R} 1=\mathrm{R} 2=1 \mathrm{k}$ and $\mathrm{C} 1=1 \mathrm{uF}$, the frequency of the gate pulse is about $714.3 \mathrm{~Hz}$ for our circuit.

The MOSFET Q5 inverts the OUT pulse of 555 timer to be applied at its Drain terminal i.e. when OUT is High, MOSFET Q5 is turned ON and 
hence its Drain voltage goes to zero. And when OUT voltage is low,Q5 is OFF, hence its Drain voltage goes High. These inverted pulses from the Drain terminals of Q5 are applied to the gate terminals of MOSFETs Q2 and Q4 in the inverter circuit. Switching Q1,Q3 alternately with Q2, Q4 in the inverter circuit produce the alternating current in the induction heating coil.

The experimental circuit, the coil is made of 200 turns of 24AWG copper wire. The measured inductance of this coil is $3.29 \mathrm{mH}$, and its resistance is $17.99 \Omega$. A $15.4 \mathrm{uF}$ available capacitance is inserted in series with the coil to reduce the effect of inductive reactance on the current in the coil. Exact capacitance for resonance in the circuit was not available during experiment.

The Figure-7 below shows sequence of gate voltages $\mathrm{V}_{\mathrm{g} 1}, \mathrm{~V}_{\mathrm{g} 2}, \mathrm{~V}_{\mathrm{g} 3}$, and $\mathrm{V}_{\mathrm{g} 4}$ to turn $\mathrm{ON}$ the MOSFETs. This figure also shows the coil current obtained by a current probe.

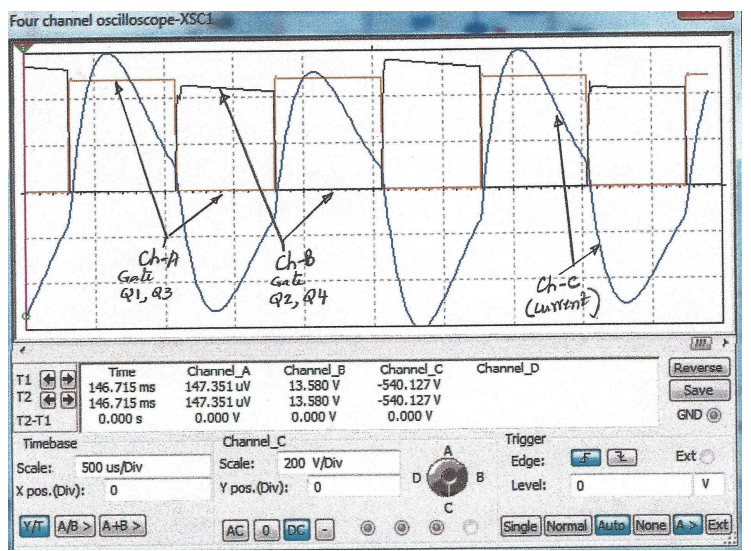

Figure-7: Gate pulses of MOSFETS Q1,Q3 and Q2,Q4, and current wave form in the coil.

The fundamental frequency of the current waveform is about $714 \mathrm{~Hz}$, same as the frequency of the gate pulses. The rms value of the current is about $0.4 \mathrm{~A}$.

When we kept the inverter $\mathrm{ON}$ for about 5 minute, the core temperature went up from $22^{\circ} \mathrm{C}$ to $29^{\circ} \mathrm{C}$, and the core flux measured was 8 Gauss $=800 \mathrm{uT}$. More heat is required to be useful for cooking. To increase more heat, more parallel coils needed to increase coil currents to increase core flux. More parallel coils with a series resonance capacitor will increase core flux for the desired heat for useful cooking. In addition, the frequency of the gate pulses can be increased for more heat.

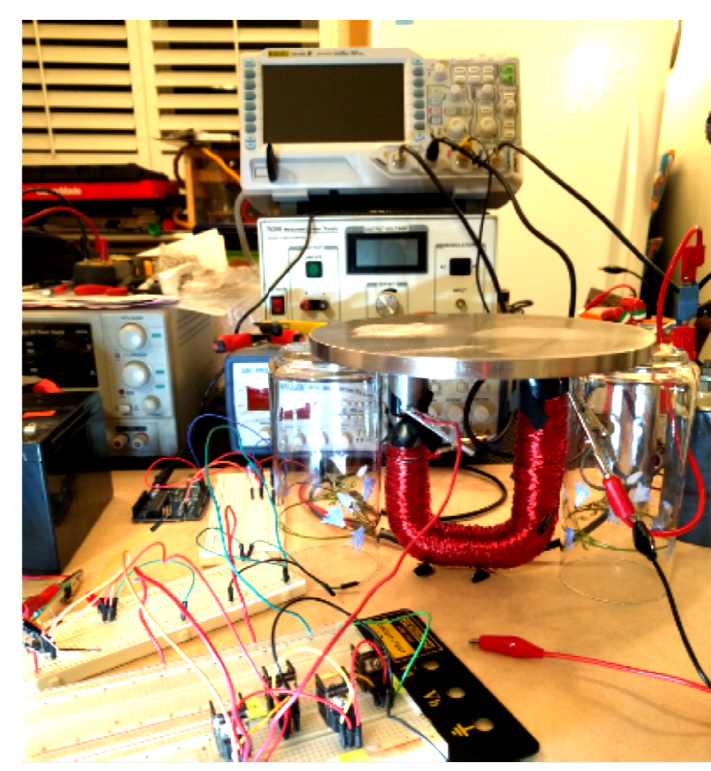

Figure-8: Experimental Setup

To increase the gate pulse frequency, R1,R2 and $\mathrm{C} 1$ in the 555 timer circuit are to be changed.

The problem of the hardware change in the 555 timer circuit can be eliminated by using a microcontroller, such as, Arduino. It is much simple to change the code of an Arduino than changing Rs and Cs in the 555 timer circuit.

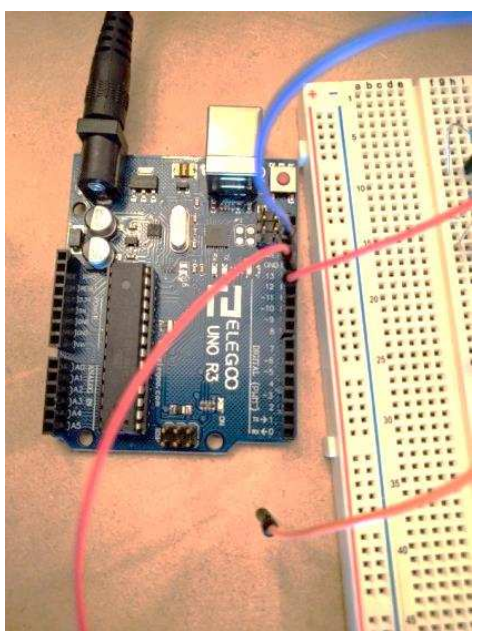

Figure-9: The adjacent picture shows the Arduino board with a breadboard beside it.

\section{A sample code to supply gate pulses to the mosfets by Arduino is shown as follows.}

// switching ON-OFF mosfets with 10ms delays //Pin 13 is connected to Gates of Q1 \& Q2 int $\mathrm{s} 12=13$;

//Pin 12 connected to Gates of Q3 \& Q4 
int s34 =12;

void setup () \{

// put setup code here, to run once:

pinMode (s12, OUTPUT);

pinMode (s34, OUTPUT);

\}

Void loop () \{

// put main code here, to run repeatedly:

digitalWrite(s12, HIGH); //Turn ON Q1 and Q2 mosfets

digitalWrite(s34, LOW); // Turn OFF Q3 and Q4 mosfets

delay(10); // wait for $0.01 \mathrm{~s}(10 \mathrm{~ms})$

digitalWrite(s12, LOW); // Turn OFF Q1 and Q2 mosfets

digitalWrite(s34, HIGH); // Turn ON Q3 and Q4 mosfets

delay(10); // wait for $0.01 \mathrm{~s}(10 \mathrm{~ms})$

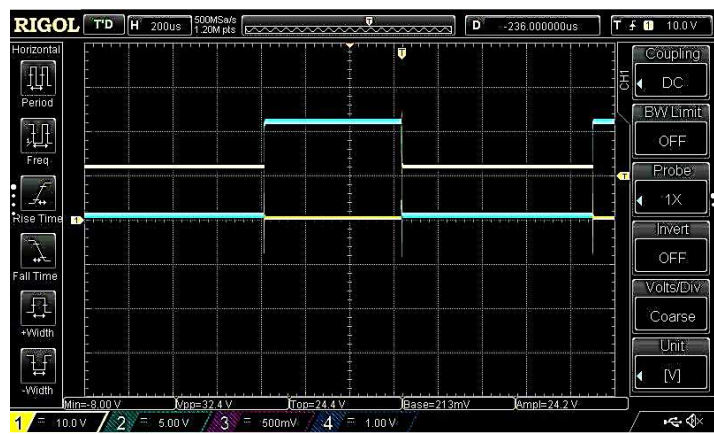

Figure-10: Yellow pulses are gate pulses for Q1,Q2 and Blue pulses are for Q3,Q4

\section{Conclusion}

This work is in progress. This paper gives initial results of the experiment. The heat produced is not enough. More parallel coils with a series resonance capacitance to be added in experiment to increase coil current and hence the core flux. The frequency of the mosfet gate signals to be increased in the improved circuit.

\section{References}

1. Maswaki Miyamae, Takahiro Ito, and others, 'Performance of high frequency QuasiResonant Inverter with variable- frequency output for induction heating', IEEE $7^{\text {th }}$ International Power Electronics and motion control conference, Harbin, China, 2012.

2. W.C. Moreland, 'The induction range: Its performance and its development problems', IEEE Transaction Industry Applications, vol.IA-9, no.1, 1973.

3. S.Karim, 'Energy Conversion', Ryerson University Book store, Toronto, 2009. 